\title{
Influence of various phytohormones on the growth and development of the Solnechny potato variety in vitro
}

\author{
O.O. Novikov", M.S. Romanova, N.I. Leonov, and E.I. Kosinova \\ Siberian Research Institute of Agriculture and Peat - branch of the SFSCA RAS, Gagarina st., 3, \\ 634050, Tomsk, Russia
}

\begin{abstract}
In the work, the study of six different nutrient medium compositions' influence on the growth and development of a healthy Solnechny potato variety in the growing process in laboratory conditions in vitro was carried out. The influence of different nutrient medium compositions on plant height, number of leaves/internodes, plant weight and total leaf surface area was studied. It was revealed that nutrient media with BAP addition cause a decrease in all of the above indicators. In addition, nutrient media with this growth regulator lead to the appearance of microtubers on the plants. It has been shown that the inclusion of GA and IAA growth regulators in nutrient media leads to a slight increase in the number of internodes. An increase in the total leaf surface area was noted in the above options. It should be noted that the nutrient medium options with the addition of GA and IAA led to a decrease in the mass and length of the root system of Solnechnyi variety potato plants.
\end{abstract}

\section{Introduction}

Potato is one of the most important agricultural crops, which occupies one of the first places in the world crop production [1,2].

Potatoes are susceptible to a wide range of diseases and pests, and due to vegetative reproduction of potatoes, the infection is transmitted along with the planting material [3]. As a result, there is an accumulation of viral, viroid and phytoplasmic pathogens, which reduce productivity and other economically valuable traits [4]. Thus, obtaining a healthy planting material is one of the significant tasks of potato seed production $[5,6]$.

The most promising direction for solving this problem is the use of clonal micropropagation methods [7, 8]. This method allows for mass and accelerated propagation of healthy potato clones in in vitro culture, which reduces the time for obtaining seed tubers. This is due to the high multiplication factor during meristemic plants' micro-grafting in in vitro culture [9]. One of the ways to increase the application efficiency of clonal micropropagation methods is to search for the optimal composition of the nutrient medium and growth regulators. The solution to this problem will increase the production of healthy

\footnotetext{
*Corresponding author: novickoww@yandex.ru
} 
planting material, as well as improve the accelerated reproduction methods of potatoes in in vitro culture [10].

The aim of this work was to reveal the regularities of various phytohormones' influence on the growth and development of Solnechny potato variety under laboratory conditions in vitro.

\section{Materials and methods}

The work was carried out at the Siberian Research Institute of Agriculture and Peat - branch of the SFSCA RAS in 2020. The object of the experiment was the improved maternal microclones of Solanum tuberosum L. Solnechny potato variety obtained from the apical meristems by cultivation on the Murashige-Skoog nutrient medium with modifications.

Before experiment's establishment, all microplants underwent real-time PCR diagnostics in the laboratory for the diagnosis and quality control of seed potatoes.

Concentrated solutions of macro-, microsalts, vitamins and phytohormones were prepared to speed up the process of nutrient medium preparation. All concentrated solutions of the required elements were labeled and stored in a refrigerator.

6 options for the composition of the nutrient medium were studied. The studied compositions are shown in Table 1.

Table 1. Composition of the nutrient medium for growing healthy potato plants, $\mathrm{mg} / \mathrm{l}$.

\begin{tabular}{|c|c|c|c|c|c|c|c|}
\hline It.No. & Name & $\begin{array}{l}\text { MS-1 } \\
\text { medium } \\
\text { (control) }\end{array}$ & $\begin{array}{c}\text { MS-2 } \\
\text { medium }\end{array}$ & $\begin{array}{c}\text { MS-3 } \\
\text { medium }\end{array}$ & $\begin{array}{c}\text { MS-4 } \\
\text { medium }\end{array}$ & $\begin{array}{l}\text { MS-5 } \\
\text { medium }\end{array}$ & $\begin{array}{l}\text { MS-6 } \\
\text { medium }\end{array}$ \\
\hline \multicolumn{8}{|c|}{ Macrosalts } \\
\hline 1 & $\mathrm{NH}_{4} \mathrm{NO}_{3}$ & 1650 & 1650 & 1650 & 1650 & 1650 & 1650 \\
\hline 2 & $\mathrm{KNO}_{3}$ & 1900 & 1900 & 1900 & 1900 & 1900 & 1900 \\
\hline 3 & $\mathrm{CaCl}_{2} 2 \mathrm{H}_{2} \mathrm{O}$ & 440 & 440 & 440 & 440 & 440 & 440 \\
\hline 4 & $\mathrm{MgSO}_{4} 4 \mathrm{H}_{2} \mathrm{O}$ & 370 & 370 & 370 & 370 & 370 & 370 \\
\hline 5 & $\mathrm{KH}_{2} \mathrm{PO}_{4}$ & 170 & 170 & 170 & 170 & 170 & 170 \\
\hline \multicolumn{8}{|c|}{ Microsalts } \\
\hline 6 & $\mathrm{H}_{3} \mathrm{BO}_{3}$ & 6,2 & 6,2 & 6,2 & 1650 & 1650 & 1650 \\
\hline 7 & $\mathrm{MnSO}_{4} \cdot 4 \mathrm{H}_{2} \mathrm{O}$ & 22,3 & 22,3 & 22,3 & 1900 & 1900 & 1900 \\
\hline 8 & $\mathrm{CoCl}_{2} \cdot 6 \mathrm{H}_{2} \mathrm{O}$ & 0,025 & 0,025 & 0,025 & 440 & 440 & 440 \\
\hline 9 & $\mathrm{ZnSO}_{4} 7 \mathrm{H}_{2} \mathrm{O}$ & 8,6 & 8,6 & 8,6 & 370 & 370 & 370 \\
\hline 10 & $\mathrm{CuSO}_{4} 5 \mathrm{H}_{2} \mathrm{O}$ & 0,025 & 0,025 & 0,025 & 170 & 170 & 170 \\
\hline 11 & $\mathrm{Na}_{2} \mathrm{MoO}_{4} 2 \mathrm{H}_{2} \mathrm{O}$ & 0,25 & 0,25 & 0,25 & 1650 & 1650 & 1650 \\
\hline 12 & KI & 0,83 & 0,83 & 0,83 & 1900 & 1900 & 1900 \\
\hline \multicolumn{8}{|c|}{ Iron chelate } \\
\hline 13 & $\mathrm{Fe}_{2} \mathrm{SO}_{4} 7 \mathrm{H}_{2} \mathrm{O}$ & 27,8 & 27,8 & 27,8 & 27,8 & 27,8 & 27,8 \\
\hline 14 & $\mathrm{Na}_{2}$-EDTA $\mathrm{H}_{2} \mathrm{O}$ & 37,3 & 37,3 & 37,3 & 37,3 & 37,3 & 37,3 \\
\hline \multicolumn{8}{|c|}{ Vitamins } \\
\hline 15 & Thiamine - $\mathrm{HCl}$ & 2,5 & 2,5 & 2,5 & 2,5 & 2,5 & 2,5 \\
\hline 16 & Pyridoxin - $\mathrm{HCl}$ & 5 & 5 & 5 & 5 & 5 & 5 \\
\hline 17 & AS-K & 2,5 & 2,5 & 2,5 & 2,5 & 2,5 & 2,5 \\
\hline \multicolumn{8}{|c|}{ Growth regulators } \\
\hline 18 & GA & - & 0,5 & - & - & - & - \\
\hline 19 & IAA & - & - & 0.1 & - & - & - \\
\hline 20 & 6-BAP & - & - & - & 0,5 & 0,5 & 1 \\
\hline
\end{tabular}




\begin{tabular}{|c|c|c|c|c|c|c|c|}
\hline 21 & NAA & - & - & - & - & 0.1 & 0.1 \\
\hline 22 & Sucrose & 30000 & 30000 & 30000 & 30000 & 30000 & 30000 \\
\hline 23 & Agar agar & 7000 & 7000 & 7000 & 7000 & 7000 & 7000 \\
\hline
\end{tabular}

During the experiment, the cuttings were cultivated at a temperature of $20-22^{\circ} \mathrm{C}$ with a photoperiod of 16/8 hours light/dark in test tubes for 28 days using the following type of lighting: OSRAM fluorescent lamps, cold daylight, $36 \mathrm{~W}$ power, section illumination - 5 thousand lux.

35 plants of each variety were grown on every option. Repetition - three-fold. On the 3rd, 7th, 14th, 21st, 28th day during the experiment, the parameters characterizing the development of plants were measured: the plant length, the root presence, the number of leaves and internodes per plant. The mass of the root system, shoot, leaves, stem and leaf area was measured on the 28 th day.

The emergence of roots was determined visually at regular intervals. The height was measured with a measuring ruler from the base of the plant to the top apical point. The number of leaves was determined by counting them on one test-tube plant.

The mass of plants with leaves, the mass of leaves and the mass of roots were determined by weighing on a laboratory balance. Scanned images of the leaves were used to determine the surface area of the leaves, which were processed using the "ImageJ" program.

Statistical processing of the results was carried out using Statistica 8.0 software package for Windows. To compare the studied values, the Mann-Whitney test was used.

\section{Results and discussion}

The results of studying the effect of different compositions of the nutrient medium on the plants' height at different periods of their development are shown in Table 2.

In table 2 and further, the studied compositions of the nutrient medium are numbered as follows:

1) Control - Murashige-Skoog medium modified for micro-grafting;

2) Murashige - Skoog medium with the addition of gibberellic acid (GA) in the amount of $0.5 \mathrm{mg} / \mathrm{l}$.

3) Murashige - Skoog medium with the addition of IAA in the amount of $0.1 \mathrm{mg} / \mathrm{l}$.

4) Murashige - Skoog medium with the addition of BAP in the amount of $0.5 \mathrm{mg} / \mathrm{l}$.

5) Murashige - Skoog medium with the addition of BAP in the amount of $0.5 \mathrm{mg} / \mathrm{l}$ and NAA $0.1 \mathrm{mg} / \mathrm{l}$.

6) Murashige - Skoog medium with the addition of BAP and NAA in the amount of 1 and $0.1 \mathrm{mg} / \mathrm{l}$.

Analysis of the data in Table 2 shows that all nutrient media with the addition of BAP led to a decrease in the plants' height of Solnechny potato variety. Statistically significant differences were recorded at almost all periods of cultivation.

Table 2. The influence of various nutrient medium compositions on the height of healthy Solnechny variety microplants, $\mathrm{cm}$.

\begin{tabular}{|c|c|c|c|c|c|}
\hline \multirow{2}{*}{$\begin{array}{c}\text { Experi } \\
\text { mental } \\
\text { option }\end{array}$} & 3 & 7 & 14 & 21 & 28 \\
\hline 1 & $0,35 \pm 0,01$ & $2,08 \pm 0,13$ & $8,18 \pm 0,38$ & $10,34 \pm 0,37$ & $12,00 \pm 0,47$ \\
\hline 2 & $0,31 \pm 0,02^{*}$ & $2,01 \pm 0,11$ & $7,40 \pm 0,31$ & $8,91 \pm 0,34$ & $10,35 \pm 0,38$ \\
\hline 3 & $0,29 \pm 0,01^{* *}$ & $2,28 \pm 0,12$ & $8,98 \pm 0,32$ & $10,36 \pm 0,30$ & $13,00 \pm 0,53$ \\
\hline 4 & $0,22 \pm 0,01 * * *$ & $1,53 \pm 0,05$ & $2,56 \pm 0,08^{* * *}$ & $2,83 \pm 0,10^{* * *}$ & $3,14 \pm 0,13^{* * *}$ \\
\hline 5 & $0,30 \pm 0,02^{*}$ & $1,43 \pm 0,06^{* * *}$ & $2,25 \pm 0,10^{* * *}$ & $3,18 \pm 0,22^{* * *}$ & $4,31 \pm 0,36^{* * *}$ \\
\hline
\end{tabular}




\begin{tabular}{|c|c|c|c|c|c|}
\hline 6 & $0,25 \pm 0,02 * * *$ & $1,62 \pm 0,08$ & $2,32 \pm 0,10^{* * *}$ & $3,20 \pm 0,22 * * *$ & $4,21 \pm 0,35^{* * *}$ \\
\hline
\end{tabular}

Notes: * the differences are significant with $\mathrm{p}<0.05$ compared to the control; ** - the differences are significant with $\mathrm{p}<0.01$ compared to the control; $* * *$ - the differences are significant with $\mathrm{p}<0.001$ compared to the control.

The results of measuring the number of leaves / internodes when growing microplants using a nutrient medium of various compositions are presented in Table 3.

Table 3. Influence of different nutrient medium compositions on the number of leaves/internodes of healthy Solnechny variety microplants, pcs. /1 plant.

\begin{tabular}{|c|c|c|c|c|c|}
\hline \multirow{2}{*}{$\begin{array}{c}\text { Experimental } \\
\text { option }\end{array}$} & \multicolumn{5}{|c|}{ Day } \\
\cline { 2 - 6 } & 3 & 7 & 14 & 21 & 28 \\
\hline 1 & $0,45 \pm 0,09$ & $3,05 \pm 0,13$ & $5,18 \pm 0,16$ & $6,61 \pm 0,17$ & $7,27 \pm 0,22$ \\
\hline 2 & $0,50 \pm 0,10$ & $3,13 \pm 0,13$ & $5,53 \pm 0,15$ & $6,53 \pm 0,19$ & $7,33 \pm 0,20^{* *}$ \\
\hline 3 & $0,30 \pm 0,07$ & $3,07 \pm 0,12$ & $5,77 \pm 0,09$ & $7,21 \pm 0,11^{*}$ & $8,47 \pm 0,11^{* *}$ \\
\hline 4 & $0^{*}$ & $3,30 \pm 0,07^{*}$ & $3,82 \pm 0,07^{* * *}$ & $4,05 \pm 0,10^{* * *}$ & $4,43 \pm 0,15^{* * *}$ \\
\hline 5 & $0,58 \pm 0,10$ & $2,75 \pm 0,12$ & $3,60 \pm 0,11^{* * *}$ & $3,99 \pm 0,14^{* * *}$ & $4,26 \pm 0,16^{* * *}$ \\
\hline 6 & $0,25 \pm 0,07$ & $2,73 \pm 0,10^{* *}$ & $3,65 \pm 0,10^{* * *}$ & $4,12 \pm 0,13^{* * *}$ & $4,42 \pm 0,17^{* * *}$ \\
\hline
\end{tabular}

Notes: * - the differences are significant with $\mathrm{p}<0.05$ compared to the control; ** - the differences are significant with $\mathrm{p}<0.01$ compared to the control; $* * *$ - the differences are significant with $\mathrm{p}<0.001$ compared to the control.

As can be seen from Table 3, the GA use for Solnechny variety potato microplants' cultivation led to a weakly pronounced increase in the number of plants' internodes on the 28 th day of cultivation (the increase was 0.06 pcs., or $8 \%$ ). This effect was more pronounced in the option with the addition of IAA to the nutrient medium. On the contrary, there was a decrease in the studied indicator in all options with the use of BAP compared to the control.

Table 4. Influence of different nutrient medium compositions on the morphological parameters of healthy Solnechny variety microplants on the 28th day of cultivation.

\begin{tabular}{|c|c|c|c|c|}
\hline $\begin{array}{c}\text { Experimental } \\
\text { option }\end{array}$ & $\begin{array}{c}\text { Root system } \\
\text { weight, g }\end{array}$ & Total biomass, g & $\begin{array}{c}\text { Root system } \\
\text { length, cm }\end{array}$ & $\begin{array}{c}\text { The total area of } \\
\text { leaf surface, } \mathrm{cm}^{2}\end{array}$ \\
\hline 1 & $0,06 \pm 0,003$ & $0,28 \pm 0,010$ & $7,00 \pm 0,25$ & $4,89 \pm 0,24$ \\
\hline 2 & $0,04 \pm 0,003^{* *}$ & $0,27 \pm 0,010$ & $5,59 \pm 0,21^{* * *}$ & $5,74 \pm 0,27^{*}$ \\
\hline 3 & $0,04 \pm 0,003^{* *}$ & $0,30 \pm 0,009$ & $6,06 \pm 0,24^{* *}$ & $6,24 \pm 0,20^{* * *}$ \\
\hline 4 & $0,01 \pm 0,003^{* * *}$ & $0,04 \pm 0,004^{* * *}$ & $3,95 \pm 0,22^{* * *}$ & $0,40 \pm 0,06^{* * *}$ \\
\hline 5 & $0,05 \pm 0,008^{* * *}$ & $0,11 \pm 0,015^{* * *}$ & $3,59 \pm 0,24^{* * *}$ & $0,43 \pm 0,06^{* * *}$ \\
\hline 6 & $0,02 \pm 0,004^{* * *}$ & $0,07 \pm 0,009^{* * *}$ & $2,69 \pm 0,22^{* * *}$ & $0,21 \pm 0,05^{* * *}$ \\
\hline
\end{tabular}

Notes: * - the differences are significant with $\mathrm{p}<0.05$ compared to the control; ** - the differences are significant with $\mathrm{p}<0.01$ compared to the control; $* * *$ - the differences are significant with $\mathrm{p}<0.001$ compared to the control.

Table 4 shows that Solnechny potato variety plants on nutrient media supplemented with GA and IAA differed from the control plants by an increase in lamina surface area. At the same time, the use of these nutrient medium modifications led to a decrease in the mass and length of the root system in comparison with the control option. The use of a nutrient medium with BAP addition in various combinations led to a significant decrease in all the studied parameters.

In addition to the noted effects, the active microtubers' formation on plants of both varieties when grown on nutrient media with the addition of BAP and BAP in combination with NAA is worth noting. 
Moreover, the calculation of the economic efficiency of using nutrient media of various compositions was carried out. The cost of different nutrient medium options is shown in table 5 .

Table 5. The cost of different nutrient medium options.

\begin{tabular}{|c|c|c|}
\hline No. & Options of the nutrient medium composition & Price per liter, rub. \\
\hline 1 & MS-1 medium (control) & 57,16 \\
\hline 2 & MS-2 medium & 57,95 \\
\hline 3 & MS-3 medium & 57,25 \\
\hline 4 & MS-4 medium & 59,46 \\
\hline 5 & MS-5 medium & 59,48 \\
\hline 6 & MS-6 medium & 61,78 \\
\hline
\end{tabular}

Comparing the data obtained as a result of the studies carried out with the cost of various nutrient medium options, the following conclusions can be drawn:

- To obtain microplants of Solnechnyi potato variety prepared for further transplantation to aeroponic installations, it is advisable to use a nutrient medium with the addition of 0.5 $\mathrm{mg} / \mathrm{l} \mathrm{GA}$.

- For the accelerated reproduction of Solnechnyi variety potato microplants, as well as for their further transplantation to aeroponic installations, it is recommended to use a nutrient medium with the addition of $0.1 \mathrm{mg} / 1 \mathrm{IAA}$.

- To obtain potato microtubers of both studied varieties in vitro, it is recommended to use culture media with the addition of BAP.

\section{Conclusions}

Nutrient media with BAP addition (in combination with NAA and without it) caused a pronounced decrease in the height of cultivated Solnechnyi variety potato plants (the decrease on the 28 th day of cultivation amounted to 74,64 , and $65 \%$ in options 4,5 , and 6 , respectively). When GA was used for growing potato microplants, a slight (by $1 \%$ ) increase in the number of internodes was observed on the 28th day. When using IAA, this effect was more pronounced (the increase was 1 pcs. or $17 \%$ ). The use of BAP, as well as the use of BAP in combination with NAA led to a decrease in the number of internodes (by 3 pcs. or $40 \%$ ). All studied compositions caused a decrease in the mass of the root system on the 28 th day of cultivation. At the same time, in the option with GA and IAA use, the mass of the root system decreased by $33 \%$, with the addition of BAP - by $83 \%$, with the addition of BAP in combination with NAA - by 17 and $67 \%$. On nutrient media with the addition of GA and IAA, an increase in the total lamina surface area was noted (by 17 and 28\%, respectively). A significant decrease in this indicator was noted in the options with the addition of BAP (92\%), BAP in combination with NAA (by 91 and 96\%). In addition, a decrease in the root system length was observed in all options (by $20 \%$ when using GA, by $12 \%$ when using IAA, by $44 \%$ when using BAP, by $49-62 \%$ when using BAP in combination with NAA).

The use of BAP as a nutrient medium component led to the formation of potato microtubers on the plants.

\section{References}

1. D. Xhulaj, B. Gixhari, Agriculture and Forestry, 4, 105-112 (2018)

2. K.G. Liljana, S. Mitrev, T. Fidanka, I. Mite, Electronic journal of Biology, 8, 45-49 (2012) 
3. N.V. Lebedeva, Abstract of diss. thesis. for the Cand. of Agric. Sci., 188 (2015)

4. V.N. Svist, V.N. Zeyruk, A.A. Molyavko, Plant protection and quarantine, 7, 20-21 (2009)

5. A.I. Adamova, O.I. Redkin, Potato growing: scientific proceed., 10 (2000)

6. E.A. Simakov, B.V. Anisimov, A.I. Uskov, A.V. Mityushkin, A.A. Zhuravlev, T.A. Veselova, Potato growing: sci. proceed. collection: materials of the coordination meeting and sci.-practical conf. dedicated to the 120th anniversary of the birth of A.G. Lorkh, 169-175 (2009)

7. A.V. Potapkina, Agricultural Science of the Euro-North-East, 3, 88-89 (2002)

8. A.I. Uskov., Yu.L. Krivoruchkin, V.A. Blinova, Potato growing in the regions of Russia. Actual problems of science and practice, 34-38 (2006)

9. B.V. Anisimov, V.V. Tulcheev, Interregional Scientific and Practical Seminar. Potato seed production in modern market conditions, 1-6 (2004)

10. S.A. Buldakov, L.P. Plekhanova, International research journal, 8 (86), 89-92 (2019) 